\title{
Transforming EFL Classes from Lecturing to Cooperative Learning
}

\author{
Haiyan Han \\ School of Foreign Languages, University of Jinan, Shandong, China
}

\begin{abstract}
It has long been acknowledged in China that the traditional frontal-lecturing approach in EFL classes prevents learners from developing their language competence because of the limited dynamic movements among students. The large size of classes makes classroom interactions and active learning extremely difficult. This paper integrates cooperative learning with EFL teaching with an attempt to explore why cooperative learning is effective to enhancing learners' academic achievement, and discuss its potential cumulative effects on students' moral growth as well as challenges in its implementation.
\end{abstract}

Index Terms - EFL, cooperative learning, language competence, moral growth

\section{INTRODUCTION}

Transforming EFL Classes from Lecturing to Cooperative Learning English has been offered as a mandated course for non-English majors at colleges all across China since the1980s. The primary aim is to developing students' abilities to use English in an all-round way, and improving their cultural and moral qualities. The prevalence of teacher-centered approach in class, however, seems to draw us further away from this goal. Teachers dominate class by lecturing ceaselessly to seemingly quiet yet inwardly recalcitrant pupils who are seated in neat rows. Student learning is planned, supervised, and eventually graded by teachers. This spoon-feeding way of teaching severely dampens students' enthusiasm in learning, and fails to guarantee their communicative abilities. The mass-produced students are unsurprisingly "deaf and dumb" even after several years of intensive exposure to the target language. What's worse, this examination-oriented method restrains the development of student potentials, creativity and moral growth. The "assembly line" in schools produces batches of knowledge holders who routinely obey and do but cannot independently think and create. The introduction of the "magic box" under the name of "computer" does not change the nature of the old paradigm of educational practice: lecturing still predominates the class with occasional student engagement and contribution.

The increasing size of EFL (English as a Foreign Language) classes makes educational "ecosystem" worse as a result of continuous enrollment in colleges since the beginning of the new millennium. Teachers in large classes are confronted with more problems than before, such as stratified academic abilities across students, and minimized "Thou-Thou" and "I-Thou" (Hawkins, 1974) interactions. Communicatively demanding activities are purposefully avoided for fear of losing control. Teachers' authoritarian role becomes helplessly fossilized. Take the college I once worked at. There were on average at least seventy students in one class, which was not uncommon in colleges throughout the country. I could only match several names with faces at the end of the first semester. My poor memory was in part responsible for that, but much would be attributed to the unusual size of class and limited interactions between us. I always felt it intimidating to address a large class, especially when I did not have much idea who my students were and what they were expecting of me. It is embarrassing for me to have come to realize that hundreds of students have come into and out of my career without direct contact with me in the seven years of teaching. I have been struggling in vain for years to provide an answer to the question: How should teachers provide and organize an authentic and dynamic environment which encourages students to get actively involved and construct their own knowledge?

Cooperative Learning (CL) can be a way out in that it can bring forth students' academic achievement, improved problem-solving strategies, critical faculties and moral growth by facilitating dynamic interactions among teachers, students and subject matter. This paper integrates CL with college English teaching with an attempt to explore why CL is effective to enhancing learner's language competence in the context of China, and discuss its potential cumulative effects on students' moral growth and challenges in its implementation.

\section{TRANSFORMED ROLE OF TEACHERS AND STUDENTS}

$\mathrm{CL}$ is a task-based and group-structured instructional method in which members in heterogeneous groups collaborate instead of competing with each other to seek attainments that are beneficial to each member with the teacher's academic and moral guidance. Both of them share the responsibility for education: teachers are no longer the authoritarians who control students' learning behaviors but perceived as knowledge promoters; students are no longer passive recipients of knowledge and skills but active discoverers and constructors of knowledge. 
I shall make a comparison between traditional EFL teaching and CL in terms of teachers' role, students' role, and view of knowledge and curriculum. Firstly, teachers, as the absolute center of the traditional regime, control all communication channels and impart linguistic and social knowledge to the subjects. Teachers, in contrast, become knowledge facilitators in CL setting responsible for offering intervention and assistance to develop students' language competence and social skills that prepare them for active contribution to society as responsible and democratized citizens. Secondly, students in traditional settings are passive knowledge consignees and mechanical users in the whole process of knowledge relay. Students within CL groups, however, take great initiatives and responsibilities for their own learning fulfilling various roles as group leaders, participants and mediators. They construct knowledge directly by investigating, negotiating and engaging. Finally, language knowledge, concepts and skills, in the traditional paradigm, are presented as something "static" to students in a fragmented and isolated manner. Students take a "bottom-up" approach to learning: they first grasp grammatical, lexical and morphological rules through rote learning and mechanical drilling, and then try to produce rule-governed English. Student-centered pedagogy emphasizes students' agency in identifying and analyzing problems, and establishing personal connections with subject matter in group dynamics. Students take a "top-down" approach to learning: they comprehend language rules and master language use through group socialization. What matters is not how much linguistic knowledge the instructors can narrate, but how the students learn and use language as a functional tool of communication.

\section{A. Dewey's Interactive Naturalism and Humanism}

The idea that people working collaboratively towards group goals are more likely to perform better academically and socially than those working in isolation is a well-established principle of Dewey's interactive naturalism and humanism.

One of Dewey's (1915) widely acknowledged ideas is that children's innate curiosity, the basis of learning experiences, enables them to be natural learners and that "the fundamental necessity is leading the child to realize a problem as his own, so that he is self-induced to attend to it in order to find out its answer" (p. 151). In his words, students naturally construct their multiple knowledge networks on the basis of their life trajectory, knowledge repertoire and mental structures of reality. Schools should create opportunities for students to be engaged in their own learning. CL ideally provides learners a collaborative and democratic setting where students in groups discover and interpret language rules, structures, and knowledge they are directly exposed to. Concepts beyond their current stages of competence can be translated into those comprehensible to them by other group members. Learning is eventually activated, reconstructed and expanded through dialogues among students in a social setting.

Sadly, the traditional way of instruction I am familiar with destroys students' curiosity: students walked into schools craving for the unknown found themselves in the end to be molded into industrialized "puppets" who feared and hated learning whatever came out of teachers' mouth. They were worn out by the old-fashioned manner of learning in which they were compelled to mimic a single and predetermined way of thinking and believing by knowledge providers and those in authority. I believed in my teens that I did everything in school for my parents and teachers. I was so anxious to finish school and make my own way into the world. It was until graduation from school that I realized that I had to relearn in my own way to be a liberated thinker and doer.

Dewey's humanism focuses on the nature of humans, giving priority to issues involving value of life, human needs, and potential abilities. Dewey (1902) declared that authentic learning will not take place unless "it must be restored to the experience from which it has been abstracted" (p. 117). His humanism suggests that learning occurs when the subject mater is adapted to be of personal relevance to learners and when it involves active participation by the learners. The traditional teaching practice is contrary to the spirit of humanism: student are forced to learn and memorize knowledge that has lost all relevance to their personal and social needs.

Education is viciously used by those privileged to maintain the status quo, to ensure that the masses think and believe in an officially authorized way. I vividly remember that my classmates and I were filled with righteous indignation when reading about established allegations about "exploitation of workers," "evil capitalism" and low efficiency of "tripartite political system" of capitalist countries in middle schools. Unfortunately, we knew from unofficial sources that these "evil capitalists" were leading the world in economy, politics, and social welfare. We painfully felt ambivalent about the gulf between the oversimplified printed knowledge and diversified reality. I never felt that detachment in the world like this before when one of my American classmates unintentionally mistook Singapore as part of China and when a seven-year-old boy told me the only thing he knew about China was dictatorships. I felt sad about that not because they knew little about my country but because that bit of knowledge came from those propagandized materials compiled by those in power who were obviously prejudiced against China. If learners, east or west, were denied the right to a comprehensive vision of the world, their knowledge acquired must be distorted from reality.

If educating is utilized deliberately as a tool of social manipulation and brainwashing, learners' daring imagination, empathy and agency for progressive changes will be unmercifully killed. Learning should be a process in which learners are exposed to all the objectivity and emancipated to "name and transform the world" (Freire, 1972) in their own discourses. Students should be sensitized to the self-evident truth that the understandings and voices of the subservient are as privileged and validated as those in power.

\section{B. Positive Effects of CL in EFL Classes}

I envision three benefits from transformation of EFL Classes from lecturing to CL. First, it provides supportive and 
expanded opportunities for learners to use the target language. Second, it contributes to students' psychological health. Finally, it promotes the democratic climate of the classroom and students' critical thinking and democratic consciousness.

CL produces high language proficiency in students. Face-to-face group work provides abundant opportunities for them to converse in language they can understand and hear language modified to meet their needs. Sometimes information coming from the teachers is very technical, but the students try to decode it to a level appropriate to their understanding. Group members, for example, when assigned a reading task, collaborate with one another towards a group goal. They read, translate and review the work together; they analyze, sift, and examine their comprehension of the materials. Students are directly exposed to both the teachers' input and different ideas, beliefs, and expressions from their peers. Their willingness to express themselves in the target language optimizes their language skills. Ironically, the only mutual interlocution between my students and I was question-and-answer in class which typically turned out to be monologues in that students were either too shy to respond in public or afraid to "stand out" among their peers. What struck me most as a student in a America was that it indeed required pains-taking courage and self-confidence to engage myself in interactions in front of the whole class. In contrast, group work could make me feel less nervous and more willing to get involved and contribute. Students engagement and engrossment in group activities, be it drawing a map of nucleus or interpreting a poem, make real learning highly possible.

Psychological health derives from two-way interactions within groups. Disease has spread into the vital "organs" of the outdated way of instruction: students' indifferent observation of teachers' lecturing is kind of psychological torture to both. Students are disempowered to resist or change, while teachers feel powerless too as they can find no way out of that overwhelming climate. In some respects, I could sense my vulnerability: a feeling of helplessness and guilt constantly struck me at the thought of the lectures I would give that day. Whenever I felt bored with my own hammering of knowledge into my audience, I would inwardly take it as a crime committed against those who should have been endowed the capacities for active learning and critical thinking. Literally, I was worn out in the mist of deepest despair. Group-structured learning may be an anecdote to that despair: peer interactions, modeling and "scaffolding" promote students' emotional maturity, social relations skills and self-esteem by encouraging respect of differences, trust, love and appropriate concessions among students. It is not only a form of class dynamism, but also a way to building life-long interactions and communicative abilities for coping with more complex challenging situations in the world. Psychological balance virtually correlates to the cultivation of a free and democratic society.

Cooperative endeavors are the pedagogy for democracy. Democracy is not an ideal, but a way of life involving socializing and learning together. Dewey believed that if children are to learn to live in thriving democracy, they must experience the process of democracy in classroom life - a process which includes substantive opportunities to make meaningful choices and build productive relationships based on genuine interpersonal respect and empathy (Dewey, 1915). In his words, students can acquire skills that qualify them for citizenship in a democracy classroom setting by undertaking projects collaboratively and work out solutions in a respectful yet critical way. In student-centered discourses, teachers' power and authority are equitably shared with students. Students correspondingly have many opportunities to share, argue and test various ideas by and for themselves. This process fosters students' self-identity which is considered indispensable for a democratic society.

Self-identity, however, is a taboo that never appears in the "dictionary" of Chinese collectivism-centered culture. Collectivism, on one hand, really helped the whole nation and individuals achieve a lot economically, politically and socially. It, however, deprived us of the freedom to think by and for ourselves, challenge those in dominance, and revolutionize the "limit-situations" (Freire, 1972). It was a frequent occurrence that collective decisions were placed above individual opinions so that individuals even did not get a chance to say "yes" to an alleged collective decision made by the privileged few. The worse part of collective norms in culture, I believe, is self-denial: we are indoctrinated to subordinate our personal ideas and interest to those of the collective. People's voices are devalued and personal wills are kidnapped by collectivism. This invisible violence is an insult to our intelligence and consciousness, and unfortunately destroys our physical and psychological well-being. Blind self-denial and excessive craze for charisma always go hand in hand, which is manifested in the Cultural Revolution in the 1960s: a reckless decision made by a person of supreme power caused inestimable financial and humane damages to the whole nation. The traditional paradigm of teaching nefariously solidifies that social inequality and powerlessness in beings. Students passively receive whatever is imparted from the teachers without real understanding and critical judgment.

Collaborative learning, in contrast, prioritizes the shaping of students' self-identity which emerges from contributing whatever resources one has to the joint efforts and common goals. Positive assessment from the teachers and peers maximizes students' participation in dialogues with others to construct their knowledge networks and endow new dimensions to their prior experiences. Cooperation experiences produce in individuals faith in their own power and elevated self-worth; it invests power in people rather than in authoritarian figures; it encourages the development of civic skills such as dialogues, equity, and negotiation. Social topics such as public welfare, official corruption, social unrest, and environmental pollution would be brought up naturally in group discussion, which helps students take a holistic approach to these issues. Mutilating truth and dwelling on "utopia" (escaping from the reality into dreams) would only breed people's doubt, distrust and even rejection of all that is inculcated to them. People's serious reflections and empathetic understanding of self and others in this complex world help them transcend the local 
"limit-situations" (Freire, 1972), which inevitably accelerates the social progress towards political impartiality, social mobility and democracy.

It is what students are exposed to in class that they project into larger context. Individual classes, despite a weak force to help transform the way students perceive themselves and the world around them, may gather momentum in the process of students' active engagement in dialogues and periodical reflections. The process is full of new unconstructed collision and fusion of beliefs and convictions. It does not matter how that change happens, but it matters in what direction that change happens. We recognize that efforts to democratizing schools can be part of a long-term struggle, and that teachers and students must be part of it rather than isolated nodes in a dehumanizing process. Hopefully, students' preliminary awareness of individual accountability helps cultivate a stance of readiness in them to engage the surrounding world.

More strikingly, teachers are democratized in their interchanges with students and subject matter. Authoritarian teachers, in most cases, exercise their powers by disempowering their students. It is no surprise that when people suppress and stigmatize others' creativity and agency they will find their soul shrunk and moral growth stagnated. Teachers can liberate themselves by ripping off their "masks" of supreme authority and dropping that intimidating mental burden. They can achieve more by freeing students from total obedience and inner barrenness in that sharing power and authority with students fuels the same qualities in teachers as in students, namely, initiatives, independent thinking and democratic awareness.

\section{Challenges: Authority Shift AND ConteXtualized Factors}

Though CL always produces academic and social gains, it represents a host of challenges to educators in terms of authority shift within the classroom and contextualized factors.

Authority shift in classroom can be disconcerting for many teachers. Many people go to extremes in teaching practice: either as an authoritarian or a permissive. I used to be a dominator in class most of the time and habitually imposed my dispositions, perceptions, and judgment on my students who were treated as objects; in other cases, I completely handed over power to them without any intervention or attention. In both cases, the communication channels between us were kept shut. I talked, if I did, to students in a condescending manner in that I have been helplessly "socialized" into the hierarchical relations I was previously exposed to as a student at school. Questions and challenges from the students alerted me to possible indications of disrespect and defiance. My several months of learning experience in this core course gives me a new insight into the perception of "inquiry and challenges": students' capacity to question and challenge is respected and encouraged; their probe and inquiry are the very indication of active involvement in and contribution to their own process of knowledge constructing.

Only those determined to make progressive transformation from unidirectional lecturing into student-engaged pedagogy that seeks to enlighten students' imagination and democratic responsibilities are courageous enough to transgress the socially established rules by sharing power with the disempowered. But that does not follow that teachers give up their control totally but that they exercise their control in an carefully planned manner. Teachers take on more responsibilities in establishing engaged pedagogy in class: they have to ensure that the groups are well structured, tasks are properly assigned, and updated assessments are provided to ensure students can benefit from group learning. Success also depends on whether teachers could "talk with" (Freire, 2005) their students and inspire in them the longing for justice, liberty, and personal rights.

Contextualized factors should be taken into serious consideration if any student-centered teaching innovation is to be effective and sustainable. The factors mainly refer to the local context and larger context, with the former specifying the classroom and school organizational structures, and the latter specifying national policies about standardized tests, collective norms in Chinese culture, and hierarchical social structuring.

Classroom and school organizational structures can be further divided into teacher beliefs, former experiences or training, student differences in academic levels, curriculum, and school cultures. How CL is implemented in class is significantly influenced by how teachers have been exposed to and perceived it. Any attempts without enough knowledge or training in this innovation may end up in failure. Students bring to class not only prior experiences, knowledge repertoire, but also individualized values and beliefs enabling them to construct meaning in spontaneous classroom discourses. In an authoritarian school setting like my college where most EFL teachers adopt the "standardized" instructional method, we are expected to follow the prescribed curriculum and "cover" certain academic materials in a given period. The power relationships could strangle any serious attempts of innovation in education. Weekly faculty meeting in my department is a case in point: the dean seated in the front of meeting room never failed to squander hours of meeting time by "engaging" everyone present in his world-for-word interpretation of written instructions of high up with his harsh voice from the microphone. The meetings were unanimously labeled by my colleagues as "a typically bureaucratic exercise of power". I painfully came to realize that I had been treating my students unfairly. Intrinsically, my daily exposure to bureaucracy and hierarchy has blunted my awareness of freedom, autonomy and openness so that I might feel legitimated and even compensated in my abused use of authority and power in my students.

Larger context also exerts a profound influence on what happens in classroom. Standardized tests become a measuring rod for assessing student performance. The qualities of humanistic education, namely inquiry for truth, 
freedom of expression and critical thinking, are too intangible to be tested quantitatively for the stakeholders. Any progressive educational attempts to reconstructing the traditional educational regime, if failed in test payoff, will be condemned by the mainstream viewpoints as an act of rebellion against orthodoxy. Few people want to take that risk by taking a different "track". To make things worse, we are all governed by some conception of cultural identity. The colonized concept of "hierarchy", core of Chinese culture, is noticeably apparent in what Confucius stated in Confucian Analects, "There is government, when the prince is prince, and the minister is minister; when the father is father, and the son is son". In his words, unconditional subservience to the superior governs social order. This inherited cultural identity hijacks everyone's social behaviors. It made me feel guilt when one of my former colleagues told me that I changed a lot after I was transferred from a teaching position to an administrative one. Her comments indicated the slight trace of bureaucracy in my behaviors which I myself was totally unaware of. It brought home to me that nothing came clean out of dying vat. Collectivism in cultures is characterized by one faith in and one voice from the authoritarian. Alternative voices, insight, and feelings, if any, would be "harmonized" physically (imprisonment at the worst) or mentally (abridged speech freedom). Teachers and students in school discourses, consciously and unconsciously, are fettered by this collectivism-centered outlook, rendering it hard to bring forth significant changes to present teacher-centered education.

The rising expectations of progressive education, however, spur educators to effect transformation in class. What students and parents expect of education is not merely knowledge and skills as a key to economic self-advancement and social mobility, but accessibility to free thinking and democratic empowerment. Education should be a set of democracy-oriented endeavors which produce thinking beings with cultural awareness, political agency, and democratic sensibilities.

\section{CONCLUSION}

It has long been acknowledged in China that the traditional knowledge-transmission approach to EFL teaching minimizes interactions between teachers and students, and fails to develop students' language skills. The large size of EFL classes makes classroom management and active learning extremely difficult. CL approach can create a student-centered and liberal environment for leaners to construct their learning and develop their moral qualities. Teachers act not only as monitors and evaluators, but also knowledge facilitators. Group members' trust and encouragement create a low-anxiety environment for students' comprehensible input and productive output. The involvement and connectedness with subject matter help reinforce their critical thinking and democratic awareness. We should make tenacious efforts to craft a democratic and open environment to ensure education is a happy, lively, and worthwhile experience. We should protect our students from attempts to paralyze our consciousness of progress and transformation. When the students feel empowered and able to engage, we win.

\section{REFERENCES}

[1] Dewey, J. (1902). The child and the curriculum. Chicago, IL: University of Chicago Press.

[2] Dewey, J. (1915). The school and society. Chicago, IL: University of Chicago Press.

[3] Freire, P. (1972). Pedagogy of the Oppressed. Harmondsworth, London: Penguin.

[4] Freire, P. (2005). Teachers a cultural workers: Letters to those who dare teach. Oxford, CO: Westview Press.

[5] Hawkins, D. (1974). The informed vison: Essays on learning and human nature. Boulder, CO: University Press of Colorado.

[6] Legge, J. (Trans.). (1893). Confucian analects. http://www.cnculture.net/ebook/jing/sishu/lunyu_en/index.html (access $11 / 11 / 2013)$.

Haiyan Han was born in Heilongjiang, China in 1976. She received his MS degree in Foreign Linguistics and Applied Linguistics from University of Jinan, China in 2009.

She is currently a lecturer in the School of Foreign Language, University of Jinan, Shandong, China. Her research interests include second language teaching and acquisition, psycholinguistics, and applied linguistics. 